\title{
VINGT-CINQ (ET UN) POÈMES DE TRISTAN TZARA: LAS ETAPAS DE SU ELABORACIÓN
}

\author{
Francisco Deco Prados \\ Universidad de Cádiz
}

\section{RESUMEN}

En este artículo me propongo aportar algunos datos para la historia de un libro clave en la formación de las vanguardias europeas de principios del siglo XX, Vingt-cinq poèmes de Tritan Tzara. En un primer momento se estudia la evolución textual del libro a partir del análisis pormenorizado de las variantes del poema inicial del volumen, «Le géant blanc lépreux du paysage». Una atención especial es consagrada al problema que plantean las pruebas de imprenta TZR 577 del fondo Tzara de la Biblioteca Doucet, identificadas por el editor de las obras completas del poeta, Henri Béhar, como las galeradas del primer libro de poemas de aquél, Mpala Garoo, proyecto abandonado en 1916. Por último, se realiza un exhaustivo estudio comparativo de la estética del libro (soporte y compaginación) relativo a las dos ediciones realizadas en vida del autor: la primera de 1918 (Zurich) y la segunda de 1946 (París).

Palabras Claves: Vanguardias poéticas. Tzara. Variantes textuales. Estética del libro.

\section{RÉSUMÉ}

Dans cet article, je me propose d'apporter quelques éléments à l'histoire d'un livre clé dans la formation des avant-gardes européennes du début du $\mathrm{xx}^{\mathrm{e}}$ siècle, Vingt-cinq poèmes de Tristan Tzara. Dans un premier temps, j'étudie l'évolution du texte à partir de l'analyse détaillée des variantes du premier poème du volume, «Le géant blanc lé- 
preux du paysage ». Je me penche tout spécialement sur le problème que posent les épreuves d'imprimerie TZR 577 du fonds Tzara de la bibliothèque Doucet, identifiées par l'éditeur des œuvres complètes du poète, Henri Béhar, comme les placards du premier recueil de poèmes de Tzara, Mpala Garoo, projet abandonné en 1916. Enfin, je fais une étude exhaustive de l'esthétique de l'ouvrage (support et mise en page) en comparant les deux éditions réalisées du vivant de l'auteur, en 1918 (Zurich) et en 1946 (Paris).

Mots CLÉs: Avant-gardes poétiques. Tzara. Variantes textuelles. Esthétique du livre.

Las pruebas documentales utilizadas en el presente estudio, fueron consultados en la biblioteca literaria Jacques Doucet de París ${ }^{1}$, que posee la práctica totalidad de los fondos existentes de la obra de Tristan Tzara. Con las debidas precauciones, ya que siempre pueden surgir sorpresas, diremos que los textos manejados constituyen probablemente el testimonio documental más completo que actualmente cabe recabar sobre el libro.

Henri Béhar, como es sabido, ha realizado la edición crítica de las obras completas de Tzara. Es ésta, por otra parte, la única de este tipo que existe de Vingt-cinq poèmes. Las correcciones que hacemos al trabajo de Béhar no pretenden en modo alguno menoscabar el ingente esfuerzo del investigador con críticas de detalle. Éste ha presentado las obras de Tzara dando informaciones esenciales sobre ellas y con un aparato crítico sumamente valioso. Ahora pretendo sólo aportar algunos datos que puedan ser de utilidad.

\section{LAS VARIANTES DE «LE GÉANT BLANC LÉPREUX DU PAYSAGE»}

He optado por presentar inicialmente el estudio de un solo poema, el primero del libro, para observar a partir del análisis exhaustivo de sus variantes, la problemática relativa a las pruebas de imprenta TZR 577 del fondo Tzara de la Doucet. Al considerar la línea documental que lleva al libro de 1918, me parece que es éste el punto principal donde tendremos que detenernos.

El texto que tomamos como base ${ }^{2}$, último revisado por Tzara, es el de Vingt-cinq-etun poèmes, Paris, Éditions de la revue Fontaine, 1946. Signatura 10.855 de la Biblioteca Jacques Doucet.

\footnotetext{
${ }^{1}$ Doucet inició en 1916 la creación de su biblioteca contemporánea. A partir de 1929, año de su muerte, la biblioteca continuará aumentando sus fondos gracias al apoyo de herederos, escritores y administración. Hay que señalar que la biblioteca fue legada por el modisto a la Universidad de París. Cuenta en la actualidad con más de 120.000 manuscritos y unos 35.000 libros que compendian la modernidad literaria francesa.

2 Entre la edición de 1918 y la de 1946, al margen de la forma global del libro, hay pocas diferencias textuales. En la última se añade un poema de 1917, « Le sel et le vin », omitido en 1918 y que aparece, sin embargo, en el manuscrito vendido a Doucet en 1922, de donde se rescata. Por otra parte, en 1946 se corrigen también algunos errores : lent grelots (en 1918) / lents grelots (en 1946); jésusfleurchemise / jésus-fleur-chemise ; belles ongles / beaux ongles ; asyle / asile ; courve / courbe. Respectivamente en « Retraite », « Sage danse mars », « Printemps », « Gare » $\mathrm{y}$ « Remarques ».
} 
Los textos contrastados (a los que, según el caso, nos referiremos por su número) son:

1) Pruebas de imprenta pertenecientes al fondo Tzara de la Biblioteca Doucet, signatura TZR2, con la descripción «Vingt-cinq poèmes. Pièces annexes. Épreuves de provenances diverses». Figuran en ellas «Le géant le lépreux du paysage» con muchas correcciones a mano y «Petite ville en Sibérie», sin correcciones.

Hoja de $38 \times 21,5 \mathrm{~cm}$. Los caracteres, elzevir, son los mismos que en las pruebas TZR 577 y que en la edición del libro de 1918, lo que traza también una línea de unión entre estos textos. Ancho de la caja: $9 \mathrm{~cm}$. Dibujo a lápiz de una cabeza de hombre en el reverso.

2) Pruebas de imprenta con correcciones a mano de un grupo de poemas identificados por Béhar como las de Mpala Garoo, signatura TZR 577. Dos pliegos de $46 \times 59,5 \mathrm{~cm}$., con cuatro columnas de texto, con dos poemas en cada una. «Le géant» ocupa un rectángulo de $16,5 \times 9 \mathrm{~cm}$., el mismo ancho de las pruebas anteriores. Sobre este poema figura escrito a lápiz y no con tinta violeta como las correcciones, el año de 1916. En la parte baja del primer pliego, que queda en blanco, aparece un dibujo de una cabeza, hecho con lápices de cera, luego un dibujo abstracto y en tercer lugar unas cuentas a lápiz. En la parte derecha de la segunda hoja el autor realizó cuatro rostros a lápiz.

3) Texto del poema publicado en la revista italiana Le pagine, $2^{\circ}$ a., $\mathrm{n}^{\circ} 7,15$ marzo 1917, pp. 101-103. Usamos la reproducción integral de la revista, Roma, Bulzoni, 2000, pp. 139-140.

4) Texto de la edición Vingt-cinq poèmes, Zurich, Collection Dada, 1918. Signatura Ad. III. 46.

5) Copia mecanografiada del libro. Signatura TZR 1. Veinticinco folios sin correcciones. Textos mecanografiados con rollos de distintas tintas, en momentos diferentes, sobre papeles desiguales.

6) Manuscrito del libro vendido por Tzara a Doucet en 1922. Signatura A. III. 15. Treinta y tres páginas escritas por una sola cara, con muy pocas enmiendas o tachaduras. Por lo que respecta a nuestro poema, lo más interesante es destacar una anotación manuscrita en la segunda hoja: con una raya a partir de dalibouli obok se da la indicación «à lire solennellement».

En la edición crítica del poemario por Henri Béhar en 1975, se parte igualmente de la publicación de 1946 como texto base. Para establecer las variantes del poema, el investigador se limita a copiar los versos que figuran en las supuestas pruebas de Mpala Garoo (con errores, como iremos mostrando) y a ofrecer sólo tres notas de comparación con el manuscrito, texto que no aporta, según creemos, en este caso, ninguna información interesante ${ }^{3}$. Parece no conocer la existencia de la galerada del poema TZR 2 ya que no

${ }^{3}$ Él mismo afirma (Tzara 1975: 641): «Comme il arrive en présence de cette sorte de mécénat, l'auteur a fourni un texte manuscrit souvent postérieur à la pré-originale et même à l'édition originale, comme le montre la comparaison que nous effectuons, en note, avec certains brouillons du fonds Tzara et les placards de Dada (Cf. «Le géant blanc », «Petite ville en Sibérie »...)». En cuanto a los placards de Dada, ninguno de estos dos poe- 
la usa ni la cita. Aunque se refiere a la prepublicación en Le pagine, no la utiliza. Aunque conoce la copia dactilografiada del libro (que coteja para otros poemas), tampoco se sirve de ella. Por último, no se detiene apenas en comparar las diferencias formales con la edición de 1918. En definitiva, su aparato de variantes queda reducido a dos pruebas documentales, una de las cuales, en verdad, no es demasiado útil.

Ahora ofrecemos el aparato de variantes del poema, mostrando en cursiva negrita el texto de 1946. Cuando hay añadidos a mano se señalan con barras oblicuas / /. Si hay tachaduras, entre galones $<>$.

\section{le géant blanc lépreux du paysage}

1,2 , : le géant le lépreux du paysage. En 3 : le géant et le lépreux du paysage.

\section{le sel se groupe en constellation d'oiseaux sur la tumeur de ouate}

Béhar señala des oiseaux en 2 incorrectamente ya que des está corregido en /d'\%

El espacio blanco tras este verso no figura en 1 ni 3. En 2 también está, señalado a mano por el autor, lo que Béhar no refleja.

dans ses poumons les astéries et les punaises se balancent

les microbes se cristallisent en palmiers de muscles balançoires

En 1 :

dans ses poumons les astéries et les punaises se balancent halo bleu /la conjonctivite/le lézard/saint/vibre dans l'oreille

les microbes se cristallisent en palmiers de muscles balançoirs [sic] les pommes de terre nagent parmi les perroquets de pierre ses microbes.

\section{En 2 :}

dans ses poumons les astéries et les punaises se balancent halo bleu la conjonctivite le lézard vibre dans l'oreille les microbes se cristallisent en palmiers de muscles balançoires les pommes de terre nagent parmi les perroquets de pierre $<$ ses $>$ /les/ microbes.

En 3, aparece ya el estado del texto base salvo por aparecer de nuevo balançoirs. bonjour sans cigarette tzantzantza ganga

En 1 y 2 aparece un acento en tzantzàntza.

bouzdouc zdouc nfoùnfa mbaah mbaah nfoùnfa

En el manuscrito (6) la última palabra se escribe znounfa.

macrocystis perifera embrasser les bateaux chirurgien des bateaux cicatrice humide propre paresse des lumières éclatantes

les bateaux nfoùnfa nfoùnfa nfoùnfa

En 1 y 2 estos tres versos figuran como sigue :

macrocystis perifera embrasser les bateaux chirurgien

des religions sphingeries paresse

les bateaux nfoùnfa nfoùnfa nfoùnfa.

mas aparecieron en la revista (cfr. en Sanouillet 1976, 2: 241-242 la lista de las contribuciones de Tzara). Por otra parte, ninguna nota a estos dos poemas hace mención de esos misteriosos borradores ni se compara con nada el estado del manuscrito. 
En 3 leemos :

macrocystis perifera embrasser les bateaux chirurgien sphingeries paresse

les bateaux nfoùnfa nfoùnfa nfoùnfa.

En 5, se omite el sintagma del primer verso chirurgien des bateaux.

En 6, cicatrice humide propre del final del primer verso, pasa al segundo verso. En éste, además aparece, junto a lumières, <lampes $>$.

je lui enfonce les cierges dans les oreilles gangànfah hélicon et boxeur sur le balcon le violon de l'hôtel en baobabs de flammes

En 1 y 3, el verso se corta en gangànfah, formando lo que sigue un nuevo verso.

les flammes se développent en formation d'éponges

\section{les flammes sont des éponges ngànga et frappez.}

En 1 leemos, en primer lugar, añadido a mano, un verso completo que no figura en el texto base y que precede a estos dos:

La presqu'île de son cour se rétrecit confiance et gonfle gonfle gonfle tête de nègre. Por lo que respecta a los dos versos separados por un espacio blanco, se dan las siguientes variantes:

les flammes se développent en <formation> /colonies/d'éponges

les flammes <sont des > /vendanges/ éponges ngànga et frappez.

En 2, estos cambios ya están incluidos :

les flammes se développent en colonies d'éponges

les flammes vendange éponges ngànga et frappez.

En 5 tenemos en baobabs de flammes se développent en formation d'éponges, lo que parece simplemente un lapsus de copista.

La separación estrófica tras el primer verso no se da en 1,2,3. Sí en los demás textos.

les échelles montent comme le sang gangà

En 1 y 2 no aparece el acento sobre la última palabra.

les fougères vers les steppes de laine mon hazard vers les cascades

les flammes éponges de verre les paillasses blessures paillasses

En 1 :

les flammes <éponges de verre> /oreilles des canaries/ les paillasses blessures l'étoile des architectures paillasses

/paillage des arbres blessures sur/

En 2 :

les flammes oreilles des canaries les paillasses blessures l'étoile des architectures paillasses

$<$ paillage des arbres blessures sur $>$

En 3 :

les flammes éponges de verre les paillasses blessures l'étoile des architectures paillasses.

Parece que el autor para la publicación de 1917 ha elegido la solución descartada en las pruebas TZR 577 y que se adopta también en los demás textos.

les paillasses tombent wancanca aha bzdouc les papillons

les ciseaux les ciseaux les ciseaux et les ombres 
Béhar al copiar las pruebas TZR 577 olvida repetir una vez les ciseaux.

les ciseaux et les nuages les ciseaux les navires

le thermomètre regarde l'ultra-rouge gmbabàba

En 1 y 2 tras este verso aparece una línea que en versiones posteriores desaparece : tschimbogo loufou hiffoufoussa ganga

Esto constituiría una prueba más de que las versiones 1 y 2 preceden a la de Le pagine, donde el verso no figura.

berthe mon éducation ma queue est froide et monochromatique mfoua loua la

En 1 y 2 encontramos:

berthe hughes mon éducation ma queue est froide et monochromatique mfoualoua-

la

les champignons oranges et la famille des sons au delà du tribord

En 2 el verso termina con à l'origine. En 1, <à l'origine $>$ al final del verso.

à l'origine à l'origine le triangle et l'arbre des voyageurs à l'origine

En 1 y 2 se omite el primer à l'origine.

mes cerveaux s'en vont vers l'hyperbole

le caolin fourmille dans sa bô̂te crânienne

dalibouli obok et tombo et tombo son ventre est une grosse caisse

Tras el primer verso, en 1 encontramos :

mes cervaux s'en vont vers l'hyperbole dalibouli

obok et tòmbo et tòmbo

<le caolin> /l'alun/fourmille dans sa boîte cranienne manhanòro ankaratra ambo$h i<l>/ b / e ́$

dalibouli obok et tòmbo et tòmbo

son ventre est une grosse caisse

en 2 leemos:

mes cervaux s'en vont vers l'hyperbole dalibouli

obok et tòmbo et tòmbo

$<$ l'alun> /le caolin/ fourmille dans sa boîte cranienne <manhanòro > <ankaratra ambohibé

dalibouli obok et tombo et tombo>

son ventre est une grosse caisse

Béhar copia mal y da manhandro, auharatra, ambohilé. No señala las palabras tachadas salvo l'alun.

En 3 ya hay igualdad con el texto base pero se grafía aún tòmbo et tòmbo. Estos acentos, por lo demás, desaparecen sólo en la edición del texto base.

En 4, por la justificación estrecha que hace dudar cuando las líneas llegan al final de la caja, no puede saberse si tras dalibouli obok et tòmbo et tòmbo, la frase son ventre est une grosse caisse constituye una parte de éste verso o pasa a ser un verso independiente como en 1, 2, 3, 5 y 6 .

ici intervient le tambour major et la cliquette

car il y a des zigzags sur son âme et beaucoup de rrrrrrrrrrrrr ici le lecteur commence à crier

il commence à crier commence à crier puis dans ce cri il y a des flûtes qui se multiplient des corails 
En 1, el segundo de estos versos se corta tras las erres (sólo 6) y luego lo que resta, en el verso siguiente, es precedido por una mano indicativa:

car il y a des zigzags sur son âme et beaucoup de rrrrr

- ici le lecteur commence à crier il commence à crier commence à crier puis dans ce cri il y a des flûtes qui se multiplient des corails.

En 2 la mano aparece tachada y los versos quedan de la siguiente forma :

car il y a des zigzags sur son âme et beaucoup de rrrrrrr (con ocho erres)

$<->$ ici le lecteur commence à crier il commence à crier commence à crier puis dans ce cri il y a des flûtes qui se multiplient des corails

En 3 :

car il y a des zigzags sur son âme et beaucoup de rrrrr (con seis erres)

ici le lecteur commence à crier il commence à crier commence à crier puis dans ce cri il y a des flûtes

qui se multiplient - des corails.

le lecteur veut mourir peut-être ou danser et commence à crier

il est mince idiot sale il ne comprend pas mes vers il crie

il est borgne

En 1 y 2 il crie forma un verso aislado. Il est borgne igualmente es verso separado. Béhar vuelve a equivocarse y escribe il crie, en su copia de 2, como en el texto de base.

En 3, igual que en 1 y 2.

En 4, ambas frases aparecen como en el texto base.

En 5 y 6, il est borgne va unido al verso precedente. Esta opción que no aparece en ninguna otra prueba textual parece de nuevo un simple lapsus y prueba quizás una filiación entre ambos textos, el manuscrito y lo mecanografiado.

il y a des zigzags sur son âme et beaucoup de rrrrrrr

En 1 aparece el adverbio ici al inicio del verso y hay 19 erres.

En 2 sigue apareciendo ici y hay 20 erres.

En 3, 4, 5, 6 desaparece el adverbio y las erres son respectivamente: 7, 7, 8, 14.

nbaze baze baze regardez la tiare sousmarine qui se dénoue en algues d'or

En 1 aparece al principio del verso - ici y luego se escribe /sous-/marine.

En 2 se borra la mano $<->$ y aparecen aún ici y sous-marine.

En 3 el verso se rompe tras sousmarine qui se.

hozondrac trac

nfoùnda nbabàba nfoùnda tata

nbabàba

En 1, 2 y 3 nfoùnda nbabàba nfoùnda tata nbàba. En 4, nbabàba es el último verso, pero como el anterior llega al extremo de la caja, no puede saberse si hay separación real o no. En 5 y 6 la última palabra es también nbabàba pero sigue en el penúltimo verso.

Las pruebas de imprenta de TZR 2 son claramente el primer estado del texto conservado, como prueban las muchas correcciones que el poeta introduce en TZR 577 respecto a ellas. Tampoco cabe duda, por la misma razón, de que ambas preceden a la publicación en Le pagine. El manuscrito es previsiblemente una copia realizada ex profeso 
en 1922 por el autor para venderlo a Doucet como muestran las pocas correcciones que hay en él y el estado textual, sin apenas cambios, como ya indicábamos, respecto a la edición de 1918. La copia dactilografiada, sin indicación de fecha, no presenta mayores cambios tampoco respecto a la edición en libro.

Como decíamos, es importante tratar más a fondo el problema de la existencia de unas posibles pruebas de imprenta de Mpala Garoo (TZR 577), por el misterio que envuelve al primer libro preparado y destruido por Tzara en 1916 y por su relación con la gestación de Vingt-cinq poèmes. Béhar da como seguro que esas pruebas corresponden a Mpala y lo más probable es que esto sea así, aunque es necesario hacer algunas puntualizaciones que consideramos importantes. Cuatro de los poemas que aparecen en estas galeradas figurarán, en cualquier caso, en Vingt-cinq poèmes. Dado que existen unas pruebas claramente anteriores a éstas, con «Le géant» y «Petite ville en Sibérie» (TZR 2) y ya que en TZR 5777 no figura este último poema, podría pensarse que el plan original de un libro en preparación para la imprenta, estaba constituido por más textos de los que figuran en TZR 577. En 1916 por otra parte (sabemos que es la fecha de composición de «Le géant» por testimonio del autor), Tzara posee ya las pruebas de imprenta de los doce poemas de TZR 577. Reproduzco las declaraciones del autor sobre el libro de poemas escrito con anterioridad a La première aventure céleste de Mr. Antipyrine (publicado este último en julio de 1916):

La plus grande partie des « 25 poèmes » date de 1917. «Le géant blanc », « Pélamide » et « Mouvement » sont écrits en 1916. Il ne me reste que peu de poèmes de cette époque. Mon premier livre de poèmes «Mpala Garoo » qui devait précéder « La I ${ }^{\text {re }}$ Aventure céleste de Mr. Antypirine », n'existe qu'en épreuves, en un seul exemplaire. C'est pendant l'hiver de 1916 que je décidai de détruire toute l'édition. Après une maladie des nerfs qui me fit souffrir beaucoup, j'avais complètement changé de directives. Je tombai, après une vie sauvage, ne connaissant aucune loi, dans une sorte de convalescence mystique. Ce mysticisme (...) était abstrait et de nature purement cérébrale (...) Cet exemplaire de Mpala Garoo doit se trouver encore dans une malle en Suisse. Mes poèmes de 1914-1915 sont peu nombreux. Je jouais avec une sentimentalité incertaine et une ironie qui résultait de la surprise des phrases banales employés. Comme je ne réagissais que par contraste, tous mes poèmes de 1916 n'étaient qu'une réaction contre les précédents, trop doux et soignés ; ils étaient d'une brutalité excessive $^{4}$.

En Dada I, de julio de 1917, se anuncia un libro con maderas de Arp y en Dada II, de diciembre de 1917, Tzara anuncia la publicación de 12 poemas con 6 dibujos de Arp. Ya que 12 poemas son los que figuran en TZR 577, ¿la cifra es una coincidencia fortuita o podría pensarse en una equivalencia entre el material de esta galeradas y lo que Tzara prepara en 1917? Ya hemos visto que en el momento de preparar Vingt-cinq poèmes, 4 de los poemas de las galeradas 577 son usados y el resto es desechado. Que éstas constituyan una parte del hipotético Mpala Garoo, nos parece bastante posible. Tzara está preparando la publicación de un poemario desde los primeros meses de 1916 y los

\footnotetext{
4 Junto al manuscrito de Vingt-cinq poèmes que Tzara vende a Doucet en 1922, figura una carta de éste al modisto donde figuran estas declaraciones. Reproducida también por Béhar (Tzara 1975: 642-643).
} 
avatares del mundo editorial y la evolución de la estética del autor hacen que el libro se vaya transformando y que no se concretice hasta Vingt-cinq poèmes. Según las declaraciones citadas, Tzara reacciona frente a sus poemas rumanos (no olvidemos que llega a Zurich en otoño de 1915, abandonando su andadura poética en lengua rumana) y que los primeros momentos en Suiza serán de gran agitación intelectual y personal (el Cabaret Voltaire, que vive sólo seis meses, abre sus puertas a principios de febrero de 1916). La supuesta crisis mística ante tanta agitación habría que situarla más bien a finales del invierno. En cualquier caso esta reacción habría que matizarla ligeramente. Por una parte, un tercio de las galaredas 577 son reutilizadas, a lo que habría que sumar otro poema de 1916: «Petite ville en Sibérie». Béhar lo data en 1917, creemos que erróneamente, ya que aparece en las pruebas TZR 2 junto a «Le géant» y ya hemos demostrado que éstas son claramente anteriores a 577. Así pues, 5 poemas de los 25 datan del periodo «enfermo» de inicios de 1916. Además, no cabe duda de que los demás poemas en el libro conectan perfectamente con el tono de «Le géant» o «Pélamide». Desde luego, hubo elementos en el conjunto de 577 que molestaron al autor y que fueron abandonados (puede explicarse si se piensa en las referencias corporales de «La femme damnée», las rimas finales de «Décomposition», el aborto maltratado de «Dada 5», etc.). Por otra parte, analizando la evolución de «Le géant», no se cumple en absoluto lo que afirma Béhar a este respecto: «Tzara (...) regrette ses excès de brutalité et suprime des formules par trop spasmodiques. Ainsi la confrontation, quand elle est posible, du manuscrit, des épreuves ou d'un état dactylographié, et du texte final, permet de suivre les phases de violence et de repentir du poète.» (Tzara 1975 : 644). Podemos ver claramente por el cotejo de las variantes de «Le géant» que las modificaciones introducidas por el autor, desde TZR 2 hasta 1918, son más de orden «formal» que de otro tipo, buscan la distribución adecuada de elementos y la fuerza expresiva, no un aligeramiento del contenido.

Por último, hemos de aclarar que la mayoría de los poemas del libro fueron publicados en revistas vanguardistas europeas antes de la publicación del libro, en 1917 (12) y en 1918 (4) (cfr. Tzara 1975: 649 y ss.). 4 de ellos en Nord-Sud, 3 en Le Pagine, 3 en Dada, 2 en Procellaria, 1 en Sic, Trossos (traducido al catalán), Crociere barbare, Cronache letterarie, La Diana, Noi, La Strada. Así pues, son 16 poemas (64\% del total) los que aparecen en 19 revistas («verre traverser paisible» se publica 3 veces, «retraite», 2) antes de junio de 1918: en diez casos en Italia, en cinco en Francia, en tres en suiza y en una ocasión en una revista catalana. Dice el autor en la ya citada carta a Doucet: «J'étais en correspondance avec A. Sabinio (...) Par lui, mon adresse se répandit en Italie comme une maladie contagieuse. Je fus bombardé de lettres de toutes les contrées d'Italie. Presque toutes commençaient avec « caro amico » mais la plupart de mes correspondants me nommaient « carissimo e illustrissimo poeta ». Cela me décida vite de rompre relations avec ce peuple trop enthousiaste.»

\section{COMPARACIÓN DE LAS DOS EDICIONES DE VINGT-CINQ POÈMES}

En primer lugar ofreceremos una descripción formal lo más exhaustiva posible de los dos volúmenes. 
TZARA, Tristan, Vingt-cinq poèmes, Zurich, Collection Dada, 1918.

Bibliothèque Littéraire Jacques Doucet, Paris. Ad. III. 46 y LRS. Ill. 41. Ejemplar este último perteneciente a Henry Kahnweiler, con su ex libris en segunda de forros. Presenta una corrección a mano en página 14: quel<le $>$ meuble. Es preciso indicar que la editorial Dilecta ha realizado una edición facsímil de la obra en 2006 que sin embargo presenta alguna pequeña diferencia con el original: el formato no coincide exactamente, siendo algo más grande: $15 \times 20,5 \mathrm{~cm}$. e incluye una hoja delantera de respeto que no existía.

Descripción analítica y noticia sobre la colección:

\section{Estructura del libro e información básica.}

Ni hoja de respeto ni portadilla.

Portada:

tristan tzara/vingt-cinq poèmes/h arp/dix gravures sur/bois/collection

dada/zurich/[grabado : el mismo de cubierta]

Reverso blanco y primer poema en $4^{\mathrm{a}}$.

Los grabados, además del de portada-cubierta, van solos en páginas: 5, 9, 19, 25, 29 , 39, 43, 46 y en 47 al final del último poema.

Página de colofón (48):

« il a été tiré/de cet ouvrage/dix exemplaires sur hollande/numérotés de un à dix/et signés par les auteurs//ces poèmes/écrits entre mil neuf cent quinze/et mil neuf cent dix-huit/ont été achévé d'imprimer/chez $\mathrm{j}$ heuberger à zurich/le vingt juin mil neuf cent dix-huit/pour la collection dada zurich/zeltweg quatre vingt-trois//du même auteur:/la première aventure céleste $\mathrm{de} / \mathrm{mr}$ antipyrine/avec des bois gravés et coloriés/par m janco »

Justificación de tirada referida sólo a los ejemplares de lujo. Según Yves Peyré (2001: 231), el resto comportaría un número no determinable de ejemplares en papel Alfa.

Estos ejemplares de la Doucet forman parte de la tirada en Alfa.

2. Páginas y lineamiento.

49 sin numerar.

Líneas por página (máx.): 37

\section{Formato}

$14 \times 19,5 \mathrm{~cm}$.

4. Papel

Alfa, color crema claro. Gramaje aproximado: 90 gr. Sin verjurado ni filigrana. Bello granulado.

\section{Tipografía.}

Elzevir cuerpo 12. No hay mayúsculas. Para títulos, una minúscula en cuerpo 20 negrita. No hay otras variaciones de tipos ni cuerpos a lo largo de la obra. Por otra parte, hay que señalar que la impresión no es muy buena, quedando por momentos escasa de tinta en los dos ejemplares consultados. 


\section{Ilustraciones.}

10 en total, de las que se repiten dos. A diferencia de lo que hubiera supuesto una estampación metálica, su presencia en el papel no es rotunda a pesar del volumen de negro que suponen. El tamaño mayoritario es de $5 \times 13,5 \mathrm{~cm}$. Primera y última, más pequeñas (5x6). Centradas, sin enmarcar. Las 8 ilustraciones grandes, a plena página. Trazos abstractos muy sugerentes ${ }^{5}$.

\section{Dedicatorias.}

Ninguna en el primer ejemplar consultado. En el segundo, doble dedicatoria del autor al marchante, la primera, probablemente de 1918: «À H. Kahnweiler/très cordial/hommage/Tristan Tzara/Zurich», en letra negra. La segunda, fechada y con el dibujo de una flor al final, escrita en azul: «Avec les années qui/passent/et l'amitié/qui reste/de/Tristan Tzara/Paris le 2(?) mars 1946».

8. Interlineado y márgenes.

Interlineado mínimo (2 mm.)

El texto es una columna de unos $5,3 \mathrm{~cm}$. de ancho, con los siguientes márgenes:

Corte: 4,2 cm. aprox.

Lomo: $4,5 \mathrm{~cm}$. aprox.

Cabeza: $3 \mathrm{~cm}$.

Pie: $3 \mathrm{~cm}$.

Los poemas se siguen en la misma página, yendo el título a unos $8 \mathrm{~mm}$ del anterior y a $7 \mathrm{~mm}$ de los versos a continuación. Los grabados a página completa, se atienen aproximadamente a los límites de la caja de texto.

\section{Encuadernación.}

Maravillosa cubierta. Rectángulo color cobre anaranjado (un quinto de la superficie total) con las letras en negro y el grabado de Arp sobre el fondo pardo grisáceo de la cartulina. Sumamente elegante. Cartulina de alto gramaje. Cejas en los cortes superiores e inferiores pero no en el delantero. Lomo mudo.

10. A propósito de la colección.

La Collection Dada editó libros de una gran altura estética. Fue creada en Zurich por Tzara y los primeros dadaístas como un proyecto que sirviera de signo de reconocimiento para el grupo trascendiendo las fronteras. De hecho, aparecen libros de la Collection Dada en Zurich, Berlín, París y Roma. Sólo aparecieron bajo este sello 13 títulos de 6 autores: Evola, Huelsenbeck, Péret, Picabia, Ribemont-Dessaignes y Tzara. Por otra parte, no era contradictorio que una editorial se hiciera cargo de la edición (como de hecho ocurre en seis casos). Vingt-cinq poèmes fue distribuido por la editorial Au Sans Pareil desde la llegada de Tzara a París en enero de 1920. En el mismo caso de distribución pero no edición por parte de Au Sans Pareil, se encuentran otras importantes publicaciones de la Collection Dada como Cinéma calendrier du coeur abstrait maisons, también de Tzara y Le passager du transatlantique de Péret $^{6}$. La mencionada editorial re-

${ }^{5}$ La lista de colaboradores plásticos en obras de Tzara es impresionante: Arp, Braque, Bryen, Dalí, Delaunay (Sonia), Ernst, Giacometti, Gris, Hugo (Jean), Janco, Kandinsky, Laurens, Léger, Marcoussis, Masson, Matisse, Miró, Nejad, Picabia, Picasso, Roger, Tanguy, Villon.

${ }^{6}$ Cfr. Fouché (1989). 
quiere, por su peso histórico ${ }^{7}$, que nos detengamos algo más en la relación entre Dadá y ella ${ }^{8}$. En enero de 1920 llega Tzara a París y su revista, Dada, llevará indicación de nueva administración en Au Sans Pareil desde marzo (para el número 7 de la revista). 391 de Picabia es confiada igualmente a Au Sans Pareil desde febrero (como lo será Cannibale). Poco después en el mismo año, sin embargo, Hilsum, su director y propietario, rechaza Jesús-Christ Rastaquouère de Picabia. Fouché (1989: 22-24) opina que el rechazo de esta publicación no fue sino la demostración de un enfriamiento entre el grupo de escritores dadaístas y Au Sans Pareil que ya se había evidenciado con la cesación de la colección de Littérature en la editorial en enero. Ni Breton, ni Aragon, ni Picabia, de hecho, volverán a publicar en ella. Tzara nunca lo hizo. Hay que indicar que, sin embargo, Dada au grand air, de septiembre de 1921, sigue en depósito en la editorial y que la revista Littérature seguirá llevando el sello de Au Sans Pareil hasta mayo de 1922. Por último, indicar que en 1928 Hilsum rechazará encargarse de la distribución de De nos oiseaux de Tzara (Fouché 1989: 63).

TZARA, Tristan, Vingt-cinq-et-un poèmes, París, Éditions de la Revue Fontaine, 1946. Collection L'Âge d'Or, dirigée par Henri Parisot. Dessins de Hans Arp.

Bibliothèque Littéraire Jacques Doucet, Paris. Signatura 10.855.

\section{Descripción analítica y noticia sobre la editorial y la colección:}

\section{Estructura del libro e información básica.}

Una hoja de respeto y portadilla con el título.

Portada:

tristan tzara vingt-cinq-et-un poèmes dessins de hans arp collection lâge d'or dirigée par henri parisot éditions de la revue fontaine

Reverso : copyright by éditions de la revue fontaine 1946.

Primer poema en $9^{a}$.

Los dibujos de Arp van solos en páginas: 13, 19, 25, 31, 37, 41, 45, 49, 53, 57, 61 . Sus reversos van siempre en blanco.

Página de colofón (67):

« de cet ouvrage achevé d'imprimer sous la direction de henri parisot le dix-huit février mil neuf cent quarante six il a été tiré/dix exemplaires sur madagascar marqués de a à j/vingt-cinq exemplaire sur arches numérotés de I à XXV/cent cinquante exemplaires sur alfa numérotés de 1 à 150/six cents exemplaires sur surglacé d'édition numérotés de 151 à 750/exemplaire 8 »

\footnotetext{
${ }^{7}$ El libro de referencia sobre ella es el de Pascal Fouché (Fouché, 1989), quien también es autor de una monografía sobre la editorial La Sirène (1984). Puede consultarse también sobre el mundo de las revistas francesas la siguiente página web: http://www.imec-archives.com.

${ }^{8}$ La editorial nace junto a la «Collection de Littérature». La idea de Breton y sus amigos era la de crear una editorial que se ocupara de los autores de la revista, creada en marzo de 1919. El número uno (de la colección y la editorial) será la plaquette Les mains de Jeanne-Marie de Rimbaud, de mayo de 1919.
} 
Esta página va precedida en la par precedente (66) de una explicación sobre la primera edición:

« les vingt-cinq poèmes ont été publiés pour la première fois en 1918 collection dada zurich avec des bois de hans arp le dernier poème du présent recueil daté de 1917 et inédit a été aimablement communiqué aux éditeurs par la bibliothèque jacques doucet ».

En página 68 figuran lo datos de imprenta (grou-radenez /paris) y el número de impresor.

Al final del libro, hoja de respeto.

2. Páginas y lineamiento.

70. Numeración en margen inferior izquierdo.

Número máximo de líneas por página: 35 .

3. Formato

$13 \times 18 \mathrm{~cm}$.

4. Papel

El ejemplar estudiado va en papel Alfa, color crema claro, bastante grueso, pero sin ningún interés particular.

5. Tipografía.

Caracteres de palo seco en cuerpo 10. No hay mayúsculas. Para títulos, la misma minúscula en negrita, sin variación de cuerpo.

6. Ilustraciones.

Formas abstractas. Su medida es variable, bien ocupando el largo de la caja (14,5 $\mathrm{cm}$.) o bien la mitad de ella. Hay que indicar que las ilustraciones no reproducen las xilografías de la edición de 1918: esas maderas fueron teóricamente destruidas tras la edición de la obra.

\section{Dedicatorias.}

Ninguna en este ejemplar.

8. Interlineado y márgenes.

Interlineado mínimo $(2 \mathrm{~mm}$.)

La caja de texto es de $9 \times 13 \mathrm{~cm}$., con los siguientes márgenes:

Lomo: $1,5 \mathrm{~cm}$.

Corte: $2,5 \mathrm{~cm}$.

Cabeza: $1,7 \mathrm{~cm}$.

Pie: $3,3 \mathrm{~cm}$.

El ancho de caja y los márgenes se acercan bastante al estándar de los libros de calidad (2/3 del ancho de página y rotación de 4, 5, 6 y 7 décimos de la diferencia entre ancho de página y de caja). Los poemas terminan página. Cuando uno termina en página impar, el siguiente va en la par consecutiva. Los títulos se encuentran a un centímetro del cuerpo del poema.

\section{Encuadernación.}

Cubierta interesante aunque fría, frialdad que procede tanto de los tipos elegidos como del color verde ácido que se combina con el negro. El libro en sí es enteramente mudo y va con un forro de solapas. En la primera de forros, en letras de cuerpo grande (minúsculas) que ocupan toda la mitad superior del rectángulo (base de color crema) apa- 
rece: tristan tzara (color negro) / vingt-cinq-et-un (color verde) / poèmes (en cuerpo bastante más grande, color verde) / dessins de hans arp (en cuerpo menor que primera línea, en color negro). Luego se abre un amplio espacio blanco y al final de la página, en cuerpo menor, aparece en verde el nombre de la colección con su director y como última línea, en negro, el nombre de la editorial. La contrabierta es muda. En el lomo, sólo el título.

\section{A propósito de la editorial y la colección.}

La revista Fontaine ${ }^{9}$ fue fundada en 1939 (aunque es hija de la revista Mithra, nacida un año antes). Apareció primero en Argel y luego en París desde 1944 hasta el año de quiebra, 1947. Su director fue Max-Pol Fouchet, gracias a cuya actividad incesante la revista jugó un papel importante durante la segunda guerra mundial, convirtiéndose, a pesar de la censura, en un elemento de apoyo a la resistencia. En ella colaboraron autores como Aragon, Artaud, Ponge o Soupault. La colección L'Âge d'Or, dirigida por Henri Parisot, publicó de 1945 a 1947 las obras de los poetas ligados a la revista. Tras el cierre de Fontaine, el director de la colección siguió publicándola con otros editores como Robert Marin, Éditions Premières y finalmente, de 1964 a 1975, Flammarion.

Al comparar el aspecto formal de las dos ediciones, vemos que la diferencia radical de la mise en page (o compaginación) ${ }^{10}$ de los dos libros marca un abismo entre ellos, a pesar de que comparten un formato similar y unas ilustraciones abstractas distribuidas aproximadamente del mismo modo. Ni el papel ni la encuadernación son determinantes en la separación estética entre ambos: en cuanto al soporte de los ejemplares consultados, es bastante más atractivo el papel alfa de 1918 que el de 1946, pero esto no marca la diferencia. Más importante es la diferencia de la encuadernación, en lo relativo a la cubierta especialmente. En el primer caso, el rectángulo color cobre pegado sobre la cartulina con el texto alineado a la izquierda y el grabado de Arp, crea un efecto de extrema belleza. En 1946 la cubierta o primera del forro efectivo que envuelve al libro es de una frialdad llamativamente neutra. El color verde elegido para las letras sans serif de gran cuerpo alternando con otras de color negro en cuerpo más pequeño aumenta, como decíamos, la sensación señalada.

El formato no sería estrictamente un elemento de la compaginación pero está en relación con ella ya que el resultado final de la mise en page dependerá en gran medida del espacio de página de que se disponga. Podríamos decir que es algo previo y al mismo tiempo unido indefectiblemente a la compaginación, por ello estudiaremos juntos estos factores. El libro de 1918 mide, como indicábamos, $14 \times 19,5 \mathrm{~cm}$. La proporción entre ancho y largo se aproxima a un factor 3/4. En cuanto a los márgenes, se atienen a una jus-

${ }^{9}$ Puede verse el libro sobre la revista de su propio director, Fouchet (1979).

${ }^{10}$ La expresión mise en page es en ocasiones usada tal cual por autores españoles. Si nos atenemos a la nomenclatura tradicional en castellano, el término correspondiente al concepto es el de compaginación, que engloba, una vez decidido el formato del libro, la estructuración del espacio visual, el contraste entre blancos y negros. Ésta conlleva establecer: «los márgenes, las interlíneas, el tipo de justificación (a renglón tendido o en columnas), el número de líneas por página, la elección de los caracteres (tipo y cuerpo), elección de ilustraciones, de las notas (...), de los títulos y su estructura, [de la paginación], del número de páginas, entre otros muchos aspectos.» (Pedraza et al. (2003: 176 y 177). 
tificación o ancho de caja muy estrecha, de 5,4 cm., con una altura de $14 \mathrm{~cm}$. Esto da una columna de texto sumamente elegante, con márgenes de corte y lomo similares: 4,5 en el corte y algún milímetro menos en el lomo. Del mismo modo, unos $3 \mathrm{~cm}$. en el margen de pie y algo menos en el de cabeza. En ningún modo estas proporciones se atienen o se acercan a las tradicionalmente usadas en los talleres de imprenta, ni para ediciones «de calidad» (como indicábamos, ancho de caja $2 / 3$ del ancho de página y rotación de márgenes de $4 / 10$ para lomo, 5 para cabeza, 6 para corte y 7 para el pie) ni para ediciones «corrientes» (proporción de 3/4) ni para ediciones que respetan el número áureo (proporción de $3 / 5)^{11}$. La originalidad de la justificación da al libro un aspecto novedoso (que indudablemente se une a la novedad del contenido), pero de una forma contenida; sobria, pero efectiva. La tipografía y los demás factores de la mise en page se alían perfectamente para contribuir a crear este efecto. Ya hemos señalado que en este libro no hay mayúsculas, ni siquiera en los títulos de los poemas (que van en elzevir minúscula cuerpo 20 negrita, el resto en cuerpo 12 normal), así como tampoco hay signos de puntuación. Esta continuidad refuerza la estilización de la columna de texto y también el hecho de que los poemas se suceden en la misma página, separados sólo por un doble espacio antes y después de cada título. Los finales de verso, que a menudo saltan a la línea siguiente no se marcan con ninguna sangría, sino que quedan alineados a la izquierda. Así, por ejemplo, al principio de «droguerie-conscience»:

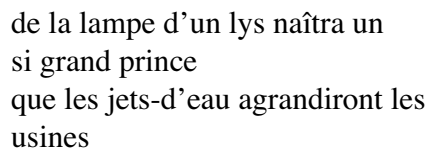

vemos que el paso de un verso a otro se marca por el blanco que queda a la derecha. En ocasiones, el verso llega por azar justo al final de la línea, lo que puede generar una duda en el lector, a la que sin duda Tzara no daba mayor importancia. Por ejemplo en «Le géant»:

\section{dalibouli oboe et tòmbo et tòmbo son ventre est une grosse caisse}

La edición en revista de 1917 y todas las demás fuentes textuales que hemos cotejado dan dos versos, lo que confirmaría la lectura separada, pero en 1946 encontramos que lo dos versos se fusionan en uno: ¿decisión de última hora o error del mismo Tzara al basarse en el texto de 1918 (donde no se puede verse la separación) y no recordar su primera idea?

En la edición de 1946, el formato es ligeramente inferior. El ancho de caja y los márgenes, como indicábamos, se acercan al estándar de los libros de calidad (proporción de ancho de caja respecto al de la página de 2/3), pero toda originalidad desaparece. Se respeta el uso continuado de la minúscula y la ausencia de puntuación, pero los márgenes son los habituales. Los poemas, además, terminan página, rompiéndose la impresión de columna continua de la anterior edición.

${ }^{11}$ Cfr. por ejemplo, para una explicación pormenorizada de los elementos de la mise en page, el libro de Perrosseaux (2003). 
Por otra parte, habría que oponer la tipografía hiperclásica Elzevir de 1918 y los caracteres de palo seco un tanto chatos de 1946. Los remates de las letras romanas acogen la mirada y van guiándola a través de la línea, lo que genera un ambiente visivo cálido y aporta fluidez. Las letras bâton (sans serif o de palo seco) sin embargo, tienden a «despedir» la línea de visión hacia arriba o hacia abajo, lo que las hace menos aptas para una lectura continuada o, en cualquier caso, las hace más frías.

Por último, habría que subrayar que la primera edición fue por cuenta de autor y decidida plenamente por Tzara mientras que la segunda fue una reedición solicitada por Parisot al autor desde la revue Fontaine (Bruhl 2001: cap. 3). La oposición entre ambas manifiesta, en cualquier caso, una muy diferente voluntad de significación tipográfica.

\section{BIBLOGRAFÍA}

BRUHL, Hélène (2001), «Tristan Tzara et le livre: ses éditeurs et ses illustrateurs», Resumen de tesis DEA defendida en 2001, disponible en Internet: http://theses.enc.sorbonne.fr/ document $37 . \mathrm{html}$

ChAPON, François (1984), Mystère et splendeurs de Jacques Doucet 1853-1929, París, Jean-Claude Lattès.

- (1987), Le peintre et le livre. L'âge d'or du livre illustré en France. 1870-1970, París, Flammarion.

DACHY, Marc (2005), Archives Dada / Chronique, París, Hazan.

Fouché, Pascal (1989) (ed. orig. 1983), Au sans pareil, París, Institut Mémoires de l'Édition Contemporaine.

Fouchet, Max-Pol (1979), Les poètes de la revue Fontaine, Paris, Le Cherche Midi.

Institut Mémoires de l'Édition Contemporaine, http://www.imec-archives.com.

International Dada Archive, Universidad de Iowa (http://www.lib.uiowa.edu/dada).

LE BON, Laurent (dir.) (2005), Dada, catalogue publié à l'occasion de l'exposition Dada présenté au Centre Pompidou du 5 octobre au 9 janvier 2006, París, Éditions du Centre Pompidou.

Le pagine (2000) [Reproducción integral de la revista], Roma, Bulzoni.

Pedraza, M. J. et al. (2003), El libro antiguo, Madrid, Síntesis.

Peyré, Yves (2001), Peinture et poésie. Le dialogue par le livre, París, Gallimard.

Perrousseaux, Yves (2003, ed orig. 1996), Mise en page et impression, Méolans-Revel, Atelier Perrousseaux Éditeur.

SANouillet, Michel (ed.) (1976-1983), Dada. Réimpression intégrale et dossier critique de la revue publiée de 1917 à 1922 par Tristan Tzara, 2 t., Nice, Centre du XXe siècle.

TZARA, Tristan (1918), Vingt-cinq poèmes, Zurich, Collection Dada.

- (1946), Vingt-cinq-et-un poèmes, París, Collection de la Revue Fontaine.

- (1975), CEuvres Complètes, t. 1, París, Flammarion. Édition d'Henri Béhar. 